\title{
Materiais cerâmicos de inserção aplicados a baterias de íons lítio
}

\section{(Intercalation ceramic materials applied in lithium ions batteries)}

\author{
N. C. Pesquero, P. R. Bueno, J. A. Varela, E. Longo \\ Centro Multidisciplinar para o Desenvolvimento de Materiais Cerâmicos, Instituto de Química - UNESP \\ C.P. 355, Araraquara, SP 14801-970 \\ nairacp@gmail.com,prbueno@iq.unesp.br
}

\begin{abstract}
Resumo
Esta revisão visa ser uma introdução à aplicação de materiais cerâmicos em dispositivos de armazenamento de energia, em especial baterias secundárias de íons lítio, dispositivos nos quais os materiais cerâmicos, especialmente óxidos, são muito importantes em todas as partes do dispositivo. A revisão está focada nos materiais cerâmicos para catodos e anodos, partes chaves destes dispositivos. Ela tem por principal finalidade ser uma fonte de informação para aqueles que desejem trabalhar com o desenvolvimento de materiais cerâmicos para tais tipos de dispositivos. Aspectos relacionados à nanotecnologia e materiais óxidos nanoestruturados para esta área são discutidos ao final do artigo.

Palavras-chave: baterias de íons lítio, reações de inserção, nanoestruturas.
\end{abstract}

Abstract

This paper aims to be an introductory text on the applications of ceramic materials to energy storage devices, mainly lithium ion secondary batteries, i.e. devices in which the ceramic materials, e.g. oxides, are very important in all parts of the device. This review is focused in ceramic materials for cathodes and anodes, which are key parts of the battery device. The main purpose is, therefore, to offer to the reader, who is interested in the development of ceramic materials for storage devices, enough information concerning the main oxide materials used nowadays and promising technology regarding nanoestructured oxides and electrode geometry based on the nanoscale.

Keywords: lithium ion battery, insertion reaction, nanoestructures.

\section{INTRODUÇÃO}

$\mathrm{Na}$ área de cerâmicas eletro-eletrônicas é bastante comum a descrição das propriedades e desenvolvimento de materiais cerâmicos, especialmente óxidos para aplicações em diferentes dispositivos, tais como sensores, varistores, termistores, eletrólitos para células combustíveis, etc. No entanto, não é comum a descrição das propriedades de materiais para aplicações em baterias de íons lítio. Sendo assim, neste texto fazemos isso com o intuito de apresentar ao público que trabalha com materiais cerâmicos a possibilidade de desenvolvimento destes materiais para esta aplicação específica.

Sendo assim, pode dizer que baterias são dispositivos compostos por um conjunto de pilhas agrupadas em série ou em paralelo, sendo que o último tipo de agrupamento é uma célula do tipo galvânica constituída por dois eletrodos e um eletrólito, arranjados de maneira a produzir energia elétrica a partir de uma energia química armazenada [1]. As baterias podem ser diferenciadas considerando-se a maneira como funcionam, sendo, portanto classificadas em: (a) baterias primárias, as quais constituem sistemas não recarregáveis, devido à ocorrência de reações paralelas, que comprometem a estabilidade da célula. Ex.: zinco/ dióxido de manganês (Leclanché), zinco/óxido de prata, lítio/dióxido de enxofre, (b) baterias secundárias, as quais constituem sistemas cujas reações eletroquímicas podem ser revertidas por meio da aplicação de uma corrente externa, sendo, portanto recarregáveis. Um sistema eletroquímico é considerado secundário quando é capaz de suportar 300 ciclos completos de carga e descarga com retenção de $80 \%$ da sua capacidade.

A idéia de empregar materiais que apresentam reações de inserção, como parte de um componente eletroquímico ativo para baterias, começou a ser explorada por volta de 1970 [2], impulsionando a busca por compostos de inserção de lítio. A razão para sua aplicação tão difundida é o fato de que as reações de inserção eletroquímicas são intrinsecamente simples e reversíveis [3].

Os compostos de inserção de íons lítio têm ganhado atenção considerável, pois podem ser usados como um eletrodo ativo em baterias recarregáveis de íons lítio, as quais possuem aplicações em potencial, desde dispositivos eletrônicos portáteis até veículos elétricos [4].

\section{Tipos de baterias}

As principais baterias primárias que se destacam no mercado são:

- Leclanché $\left(\mathrm{Zn} / \mathrm{MnO}_{2}\right)$ : composta por um anodo de 
zinco metálico, um bastão de grafite cilíndrico rodeado por uma mistura em pó de dióxido de manganês e grafite como catodo e uma mistura de cloreto de amônio e cloreto de zinco como eletrólito. Esta pilha fornece um potencial de circuito aberto no intervalo de 1,55 a 1,74 V. Para aplicações que requerem valores baixos e médios de corrente elétrica este tipo de pilha apresenta uma relação custo-benefício interessante. Os principais inconvenientes encontrados são as chamadas reações de prateleira, as quais ocorrem durante $\mathrm{o}$ armazenamento e durante o período que permanecem em repouso, podendo provocar vazamentos. Este problema é minimizado, pelos fabricantes, com a adição de sais de mercúrio solúveis no eletrólito, fazendo com que esse tipo de pilha represente sérios riscos ao meio ambiente.

- Lítio/dióxido de manganês: pilhas primárias que empregam lítio como anodo, representam sistemas eletroquímicos de pequenas dimensões, duráveis, confiáveis e capazes de armazenar grande quantidade de energia. Estas células utilizam o $\mathrm{MnO}_{2}$ como catodo (sólido com baixa solubilidade no eletrólito) e como eletrólito um sal de lítio dissolvido em um solvente não-aquoso, pois o lítio metálico reage com água. Este tipo de pilha fornece um potencial de circuito aberto no intervalo de 3,0 a $3,5 \mathrm{~V}$, não apresenta reações de prateleira e mostra um excelente desempenho. Um inconveniente encontrado é que pilhas vedadas de maneira imprópria podem expor o lítio à umidade do ar e provocar chamas no metal e no solvente não-aquoso.

As baterias secundárias diferentemente das primárias são usadas principalmente em aplicações que requerem alta potência, sendo as mais comumente encontradas:

- Baterias chumbo/ácido: estas apresentam a característica pouco usual de envolver em ambos os eletrodos o mesmo elemento químico, o chumbo. Quando no estado carregado um único par de eletrodos apresenta um potencial de $2,15 \mathrm{~V}$. O tipo de bateria chumbo/ácido predominantemente marcante é a automotiva, a qual é usada em veículos e consiste de seis conjuntos de eletrodos na forma de placas, contidos em vasos independentes. Este tipo de bateria funciona a base de chumbo, um metal pesado e tóxico, portanto representa um sério risco ao meio ambiente.

- Baterias de cádmio/óxido de níquel: esta consiste de um anodo formado por uma liga de cádmio e ferro e um catodo de hidróxido de níquel (III) imersos em uma solução aquosa de hidróxido de potássio. Um único par de eletrodos deste tipo de célula fornece um potencial de circuito aberto de 1,5 $\mathrm{V}$, aproximadamente. Este tipo de bateria se caracteriza por apresentar altas correntes elétricas, capacidade de operar a baixas temperaturas e longa vida útil, mas o custo de sua produção é bem maior do que as baterias chumbo/ácido. Essa bateria por apresentar cádmio em sua composição é considerada de grande impacto ambiental.

- Baterias de íons lítio: neste tipo de bateria são utilizados apenas íons lítio, os quais estão presentes no eletrólito na forma de sais de lítio dissolvidos em solventes não aquosos. Os eletrodos são formados, geralmente, por compostos de estrutura aberta, denominados compostos de intercalação. A grande vantagem é a conciliação de um potencial negativo de anodos de inserção de íons lítio com um alto potencial associado ao catodo de inserção de lítio. No anodo, geralmente o grafite é o material mais comumente usado, pois além de apresentar uma estrutura lamelar é capaz de intercalar reversivelmente os íons lítio sem alterar significativamente a sua estrutura. O catodo é composto, geralmente, de um óxido de estrutura lamelar $\left(\mathrm{LiCoO}_{2}, \mathrm{LiNiO}_{2}\right.$ etc.) ou espinélio $\left(\mathrm{LiMnO}_{2}\right)$, sendo o óxido de cobalto litiado o material mais freqüentemente utilizado.

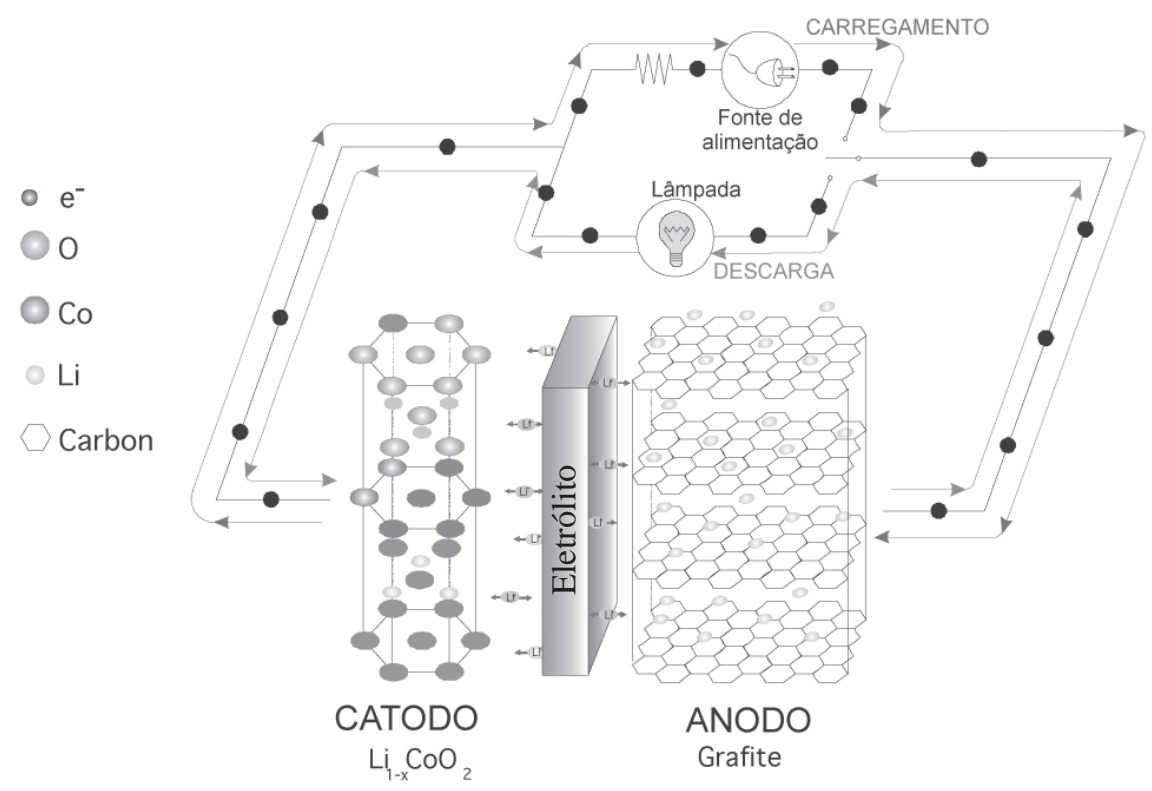

Figura 1: Diagrama esquemático de uma bateria recarregável de íons lítio [49].

[Figure 1: Schematic representation of an ion lithium battery [49].] 
Durante a descarga da bateria ocorre no anodo oxidação do carbono com conseqüente liberação de íons lítio:

$$
\mathrm{Li}_{\mathrm{y}} \mathrm{C}_{6} \rightarrow \mathrm{C}_{6(\mathrm{~s})}+\mathrm{yLi}^{+}{ }_{\text {(solv) }}+\mathrm{ye}^{-}
$$

No catodo ocorre a redução do cobalto, o que provoca a entrada de íons lítio em sua estrutura:

$$
\mathrm{Li}_{\mathrm{x}} \mathrm{CoO}_{2(\mathrm{~s})}+\mathrm{yLi}^{+}{ }_{(\text {solv })}+\mathrm{ye}^{-} \rightarrow \mathrm{Li}_{\mathrm{x}+\mathrm{y}} \mathrm{CoO}_{2(\mathrm{~s})}
$$

Sendo, portanto, a reação global de descarga dada por:

$$
\mathrm{Li}_{x} \mathrm{CoO}_{2(\mathrm{~s})}+\mathrm{Li}_{\mathrm{y}} \mathrm{C}_{6} \rightarrow \mathrm{Li}_{x+y} \mathrm{CoO}_{2(\mathrm{~s})}+\mathrm{C}_{6(\mathrm{~s})}
$$

As baterias secundárias de lítio possuem um elevado potencial de operação $(4,0 \mathrm{~V})$ e alta densidade de energia, os quais estão relacionados às propriedades peculiares do lítio, por este ser um metal leve e possuir o potencial de redução padrão mais negativo $(-3,0 \mathrm{~V})$, em relação ao par redox padrão de hidrogênio a $25^{\circ} \mathrm{C}$. Devido a essas propriedades o lítio metálico também pode ser aplicado como anodo $[1,5]$. As baterias de íons lítio apresentam riscos ambientais muito menores do que as demais baterias citadas anteriormente.

Baterias secundárias de lítio compostas de um catodo de cobaltato de lítio $\left(\mathrm{LiCoO}_{2}\right)$ e um anodo de grafite, como ilustrado na Fig. 1, foram primeiramente comercializadas pela Sony Energytech Incorporation em 1991, sendo este fato o impulsionador do desenvolvimento de novos materiais eletródicos (catodos e anodos) e eletrolíticos. Sendo assim, as pesquisas para o desenvolvimento e otimização de algumas propriedades como reversibilidade, densidade de energia e processamento, têm sido realizadas com o objetivo principal de se obter baterias com melhor desempenho a um menor custo de fabricação.

\section{PRINCÍPIOS DE FUNCIONAMENTO DAS BATERIAS DE ÍONS LÍTIO}

No processo de carga de uma bateria secundária de lítio, esta atua como uma célula eletroquímica; os íons $\mathrm{Li}^{+}$são desinseridos do catodo (C), caso este seja um material litiado, sob a ação de um campo externo provocando a oxidação de um elemento de transição de valência variável $\left(\mathrm{M}_{\mathrm{ne}}{ }^{-}\right)$presente neste eletrodo, Equação D. Os íons $\mathrm{Li}^{+}$migram através do eletrólito até o anodo, onde são reduzidos com a chegada dos elétrons que o catodo entrega ao circuito externo, Equação E, produto do processo de oxidação anteriormente descrito. No processo de descarga (desinserção dos íons $\mathrm{Li}^{+}$do anodo e reinserção no catodo) ocorrem os processos redox inversos espontaneamente [2, 6-8]. A bateria neste caso se comporta como uma célula galvânica. Este processo, mais precisamente, é que permite identificar os eletrodos (anodo e catodo). A reação química produz uma diferença de potencial, a qual quando o circuito é fechado exteriormente, permite a realização de trabalho. As equações que descrevem o processo de carga, partindo de um catodo litiado são:

Eletrodo positivo (catodo):

$$
\mathrm{C}\left(\mathrm{Li}_{x} \mathrm{M}_{\mathrm{ne}}\right) \rightarrow \mathrm{C}\left(\mathrm{Li}_{1-x} \mathrm{M}_{\text {ne xe }}^{-}\right)+x \mathrm{Li}^{+}+x \mathrm{e}^{-}
$$

Eletrodo negativo (anodo):

$x \mathrm{Li}^{+}+x \mathrm{e}^{-} \rightarrow \mathrm{Li}_{(\mathrm{s})}$

São conhecidas duas formas em que se pode inserir e desinserir o íon $\mathrm{Li}^{+}$no material catódico [6-8]: como uma reação de deslocamento ou heterofásica ou como uma reação de formação de uma solução sólida ou monofásica. Nas reações heterofásicas, os produtos inicial e final estão presentes simultaneamente enquanto dura a reação. Nas monofásicas, em cada momento existe somente uma fase, ainda que a composição varie ao longo da reação. Pode-se pensar em uma reação heterofásica como um processo no qual a fase litiada desloca a fase não litiada desde a superfície até o interior do sólido. Contudo, na reação monofásica todos os microcristais acessíveis inserem lítio simultaneamente, distribuindo-se de forma homogênea em todo o volume do material.

A curva de inserção/desinserção (voltagem vs. composição) que é obtida quando uma reação é heterofásica é aquela que apresenta uma zona plana e definida (Fig. 2a); quando a reação é monofásica apresenta-se uma ligeira inclinação na curva (Fig. 2b). Para entender esta diferença nas formas das curvas tem-se recorrido [6-8] à regra de fases de Gibbs, onde o número de graus de liberdade possível em um sistema é igual ao número de componentes menos o número de fases mais dois. Para o mesmo número de fases que de componentes, como é o caso de uma reação heterofásica, a pressão e temperatura constantes, não há graus de liberdade e, portanto, o potencial da bateria não varia. O oposto pode ser comprovado para uma reação monofásica.

As reações químicas de carga e descarga de uma bateria de Li têm lugar somente nos eletrodos. Geralmente, o eletrólito não tem participação nas reações. Assim que os

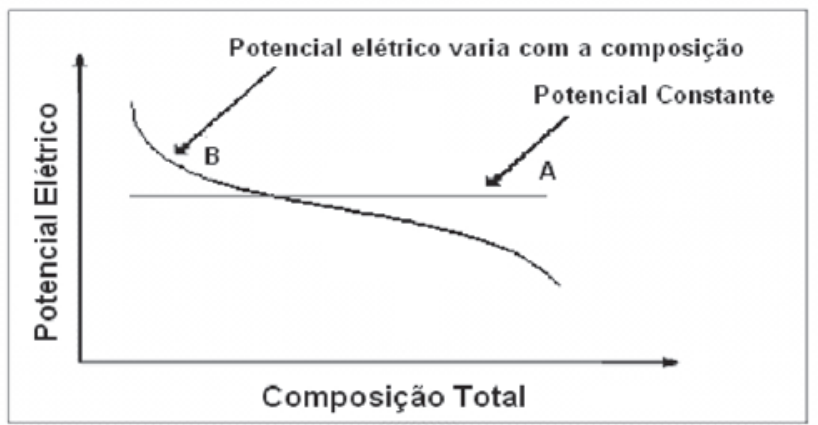

Figura 2: Tipos de reações de carga ou descarga que podem ocorrer em uma bateria secundária de Li. (A) representa uma reação heterofásica; (B) uma reação monofásica.

[Figure 2: Charge/discharge type reactions possible to occur in a Li secondary battery. (A) represents a heterophasic reaction; (B) a monophasic reaction.] 
íons lítio são oxidados e reduzidos, respectivamente, nas interfaces anodo-eletrólito e catodo-eletrólito, a força motriz para a difusão do lítio a partir da interface e em direção ao interior dos eletrodos é o gradiente de potencial químico do lítio neutro dentro destes eletrodos [9].

Nestes processos de transporte dos íons $\mathrm{Li}^{+}$no interior do catodo, os elétrons (e-) devem ser considerados porque qualquer mudança na composição dos componentes eletroativos deve ser acompanhada por mudanças na concentração dos portadores de cargas eletrônicas. Por outro lado, qualquer movimento de um destes dois tipos de cargas irá gerar um movimento do outro para manter a eletroneutralidade dentro do catodo. $\mathrm{O}$ íon $\mathrm{Li}^{+}$é que determina a velocidade do processo, mas seu movimento pode ser aumentado drasticamente pelo campo elétrico gerado internamente pelos elétrons [9]. Tem-se demonstrado que, sob a influência de gradientes de ambas as espécies $\left(\mathrm{Li}^{+}\right.$ e e-) em um condutor misto onde os elétrons se movem com maior velocidade que os íons $\mathrm{Li}^{+}$e ao mesmo tempo estão em menor concentração que estes, favorece-se a condução de íons $\mathrm{Li}^{+}$porque as espécies eletrônicas tendem a moverse diante dos íons, criando-se uma separação local das cargas. Ou seja, é gerado um campo elétrico no interior do catodo que acelera as espécies mais lentas e retarda as mais rápidas para manter a neutralidade de carga. Desta forma a natureza dos portadores eletrônicos, em igualdade de outros requisitos como os estruturais, pode impulsionar ou retardar a difusão dos íons eletroativos.

\section{MATERIAIS CERÂMICOS PARA BATERIAS}

\section{Compostos de inserção de lítio}

Um composto de inserção de lítio consiste em uma matriz anfitriã, de onde e até a qual migram, reversivelmente, os íons $\mathrm{Li}^{+}$durante os processos de inserção e extração (deinserção), sem que este processo afete substancialmente a estrutura cristalina da matriz, ou as mudanças se limitem a pequenos deslocamentos em nível atômico (reação topotáctica) [2, 6-15]. A espécie hospedeira nestas reações deve ser neutra (como a molécula de água nas argilas), aceptora de elétrons (como o oxigênio na estrutura do $\mathrm{Ba}_{2} \mathrm{YCu}_{3} \mathrm{O}_{2}$ ) ou doadora de elétrons (como o lítio nas baterias secundárias). Os materiais de inserção de lítio são diversos, tanto em composição química como em disposição estrutural. Os primeiros trabalhos realizados foram em materiais catódicos, tais como: $\mathrm{TiS}_{2}, \mathrm{WO}_{3}, \mathrm{~V}_{2} \mathrm{O}_{5}, \mathrm{MnO}_{2}[2,6-11,14,15]$, os quais foram avaliados em baterias primárias com anodos de lítio metálico, mas as dificuldades destes materiais para oferecerem diferenças de potenciais adequadas à bateria impediram a aplicação dos mesmos. Mais tarde foram testados os selenetos de metais de transição, trissulfetos de fósforo [2, 6. 8. 10, 14], e mais recentemente, os óxidos mistos e simples de metais de transição [2, 7-11, 14-20] e os compósitos [21-29].

Com respeito às considerações estruturais, quase todas as investigações e comercializações de materiais catódicos têm se centrado em duas classes de materiais. A primeira classe contém compostos lamelares com um empacotamento compacto, ou quase compacto, de ânions, os quais formam camadas alternadas que estão ocupadas por metais de transição sendo que os íons lítio encontram-se inseridos nas lâminas vazias [2, 7, 9, 14,16-18]. Este grupo é exemplificado pelos seguintes materiais: $\mathrm{LiTiS}_{2}, \mathrm{LiCoO}_{2}$ e $\mathrm{Li}_{1-\mathrm{x}^{\prime}} \mathrm{Ni}_{2+2 \mathrm{x}} \mathrm{Ni}_{3+1-\mathrm{y}-\mathrm{x}^{\prime}} \mathrm{Co}_{3+\mathrm{y}} \mathrm{O}_{2}\left(0 \leq \mathrm{x}^{\prime} \leq 0,6 \mathrm{y} \leq 1\right)$, os quais são particularmente suscetíveis às reações de intercalação devido à presença de forças fracas de Van der Waals entre as cadeias de átomos (fortemente unidos). Os compostos com estrutura espinélio podem ser considerados como uma classe especial, nos quais os metais de transição se ordenam em todas as camadas.

Os materiais do segundo grupo possuem estrutura mais aberta, como os óxidos de vanádio e os dióxidos tunelados de magnésio $[2,14]$.

\section{Materiais catódicos}

Numerosos materiais de inserção/intercalação têm sido propostos para desempenhar o papel de catodo em baterias recarregáveis de íons lítio. Com o intuito de otimização, o desenvolvimento de catodos para baterias secundárias de lítio tem sido objeto de pesquisa desde a década de 70. Para isso óxidos de metais de transição têm sido intensamente estudados para a aplicação como catodos. Na Tabela I são apresentadas à capacidade específica e a densidade de carga teórica para alguns materiais de inserção utilizados como catodo. Os principais requisitos que um material catódico deve possuir para que possa ser empregado com êxito são: (i) o íon do metal de transição deve ter uma função de trabalho alta, quando no composto de inserção, para maximizar a voltagem da célula; (ii) o composto de inserção deve permitir uma inserção/extração de uma quantidade grande de lítio para maximizar a capacidade da célula; (iii) o composto de inserção deve possuir um mínimo de mudanças estruturais em função da composição de lítio, a qual garante boa reversibilidade do processo; (iv) estabilidade química para ambas as formas redox do catodo; $(v)$ o composto de inserção deve suportar a boa condutividade iônica do $\mathrm{Li}^{+}$ e eletrônica para maximizar a polarização da célula; (vi) o perfil do potencial deve ser relativamente contínuo, sem

Tabela I - Características dos principais materiais catódicos usados em baterias de íons lítio [3].

[Table I - Characteristics of the main cathodic materials used in ion lithium batteries [3].]

\begin{tabular}{cccc}
\hline $\begin{array}{c}\text { Material } \\
\text { catódico } \\
\text { descarregado }\end{array}$ & $\begin{array}{c}\text { Massa } \\
\text { molecular } \\
(\mathrm{g})\end{array}$ & $\begin{array}{c}\text { Capacidade } \\
\text { específica } \\
\left(\mathrm{AhKg}^{-1}\right)\end{array}$ & $\begin{array}{c}\text { Densidade } \\
\text { de carga } \\
\left(\mathrm{AhL}^{-1}\right)\end{array}$ \\
\hline $\mathrm{LiNiO}_{2}$ & 97,87 & 192 & 706 \\
$\mathrm{LiCoO}_{2}$ & 97,63 & 137 & 919 \\
$\mathrm{LiMn}_{2} \mathrm{O}_{4}$ & 180,82 & 148 & 634 \\
\hline
\end{tabular}


grandes pulos de voltagem que possam complicar o controle da energia nas baterias. Portanto, de um ponto de vista comercial, o material de inserção deve ser de baixo custo, ambientalmente benévolo e leve para minimizar o peso da bateria[30], além de alta capacidade de armazenamento de energia que está diretamente relacionada com sua capacidade de inserção reversível de lítio na estrutura cristalina.

Os óxidos lamelares de metais de transição da série $\mathrm{LiMO}_{2}(\mathrm{M}=\mathrm{Co}, \mathrm{Ni}, \mathrm{Mn})$ têm muita repercussão no possível uso como catodos em baterias de íons lítio [2, 6-10, 14, 16$19,22,31,32]$, devido a alta variabilidade de seus estadosde oxidação (II-IV), alta voltagem em seu estado carregado (3 V), assim como a flexibilidade estrutural que apresentam quando se desinsere ou se insere $\mathrm{Li}^{+}$eletroquimicamente (mudanças inferiores a 10\% dos parâmetros de cela). Dentre estes óxidos destacam-se os óxidos com estrutura do tipo rocksalt lamelar $\left(\mathrm{LiMO}_{2}\right.$, sendo $\left.\mathrm{M}=\mathrm{Co}, \mathrm{Ni}\right)$ e óxidos de manganês com estrutura espinélio $\left(\mathrm{LiMn}_{2} \mathrm{O}_{4}\right)$. Esses óxidos são caracterizados pela natureza altamente oxidante e reversibilidade de intercalação de íons lítio em $3 \mathrm{~V}$ vs. Li.

$\mathrm{O} \mathrm{LiNiO}_{2}$ é um material catódico muito promissor, pois possui uma elevada capacidade de carga além de apresentar um baixo custo devido à utilização do níquel. Em questões ambientais este material apresenta-se menos agressivo. Apesar das vantagens deste material, o $\mathrm{LiNiO}_{2}$ é de preparação muito difícil quando comparada com $\mathrm{LiCoO}_{2}$ e $\mathrm{LiMn}_{2} \mathrm{O}_{4}$. Esta dificuldade de síntese está relacionada à tendência de formação de uma fase de fórmula geral $\mathrm{Li}_{1-\mathrm{x}} \mathrm{Ni}_{1+\mathrm{x}} \mathrm{O}_{2}$ com cátions $\mathrm{Li}^{+}$e $\mathrm{Ni}^{3+2+}$ desordenados, deteriorando, assim, a estrutura lamelar e, portanto, o comportamento eletroquímico do sistema [33]. Portanto existe uma dificuldade muito grande na síntese do óxido $\mathrm{LiNiO}_{2}$ estequiométrico por meio de reações de estado sólido a altas temperaturas. Um modo de resolver este problema é utilizando compostos de $\mathrm{Ni}(\mathrm{III})$ como material de partida e diminuir a temperatura de síntese. A baixa temperatura de síntese possui como vantagens, a facilidade no processo sintético e a diminuição da desordem estrutural, a qual ocorre em altas temperaturas de síntese [34]. Palacin [35] e Maruta [36] sintetizaram este óxido com uma capacidade específica de 120-140 mA.h.g ${ }^{-1}$ utilizando como material de partida o $\mathrm{NiOOH}$ obtido a partir da oxidação de $\mathrm{K}_{2} \mathrm{~S}_{2} \mathrm{O}_{8} \mathrm{e}$ $\mathrm{LiOH}$, e uma temperatura de calcinação de $400{ }^{\circ} \mathrm{C}$.

Yanzhi et alii [37] estudaram o óxido $\mathrm{LiNiO}_{2}$ calcinado a $550{ }^{\circ} \mathrm{C}$ por $20 \mathrm{~h}$, o qual também foi caracterizado eletroquimicamente. A Fig. 3 mostra a curva de carga/descarga com os primeiros 20 ciclos em densidade de corrente de $0,5 \mathrm{~mA} \cdot \mathrm{cm}^{-2}$. Este catodo exibe uma capacidade específica inicial de carga e descarga de 183,4 e 169,5 mA.h.g ${ }^{-1}$, respectivamente. Após 20 ciclos, a capacidade específica de descarga de tal material é $155,8 \mathrm{~mA} \cdot \mathrm{h}_{\mathrm{g}}{ }^{-1}$ e a retenção cíclica é aproximadamente $91,9 \%$. A boa propriedade cíclica do óxido $\mathrm{LiNiO}_{2}$ sintetizado a baixa temperatura é um benefício da boa reversibilidade intrínseca do precursor, i.e. $\mathrm{NiOOH}$.

Devido à dificuldade em sintetizar compostos de níquel, materiais alternativos de tipo $\mathrm{LiNi}_{x} \mathrm{Co}_{1-\mathrm{x}} \mathrm{O}_{2}$ vêm sendo estudados. Esse material acumula as vantagens do $\mathrm{LiNiO}_{2}$

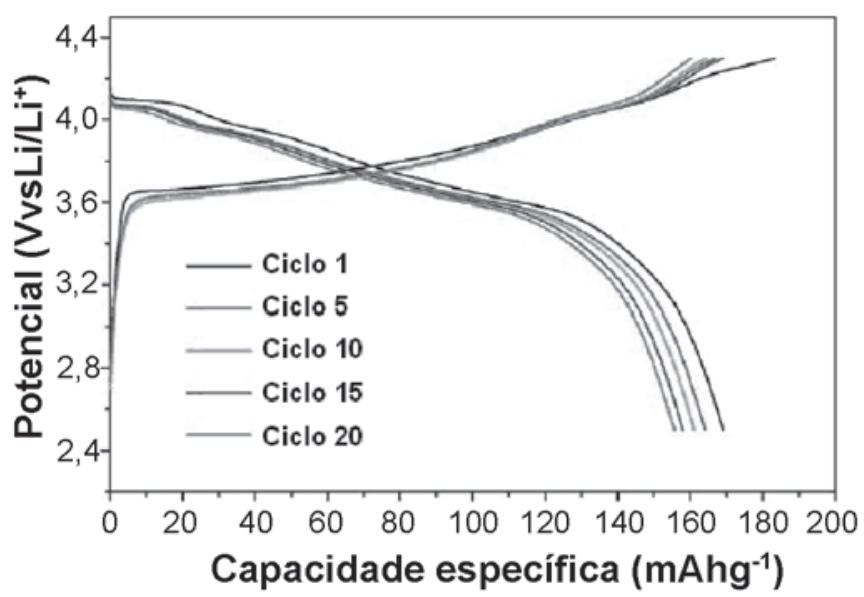

Figura 3: Curvas carga/descarga (20 ciclos) do catodo $\mathrm{LiNiO}_{2}$ a corrente constante de $0,5 \mathrm{~mA} . \mathrm{cm}^{-2}$ [37].

[Figure 3: $\mathrm{LiNiO}_{2}$ charge/discharge curves (20 cycles) at constant current of $0.5 \mathrm{~mA} . \mathrm{cm}^{-2}$ [37].]

e $\mathrm{LiCoO}_{2}$, e é facilmente obtido em sua estrutura lamelar. Entretanto, quando comparado ao $\mathrm{LiNiO}_{2}$ em relação à capacidade de carga e ciclabilidade, não é observado um melhor desempenho destes catodos $\left(\mathrm{LiNi}_{\mathrm{x}} \mathrm{Co}_{1-\mathrm{x}} \mathrm{O}_{2}\right)$ [38]. Pensava-se que a formação de $\mathrm{Li}_{2} \mathrm{CO}_{3}$ na superfície do eletrodo fosse a principal razão da pobre propriedade de estocagem de materiais baseados em $\mathrm{LiNiO}_{2}$ [39]. Descobriuse que o carbonato de lítio não é somente eletroquimicamente inativo devido a sua pobre condutividade eletrônica e a baixa condutividade de íons lítio, mas também causa, facilmente, a evolução de gás durante a operação da bateria [39].

Liu et alii [39] sintetizaram o material catódico $\mathrm{LiNi}_{0,8} \mathrm{Co}_{0,2} \mathrm{O}_{2}$ e avaliaram sua estabilidade quando exposto ao ar. As curvas de carga e descarga das amostras expostas a diferentes atmosferas são apresentadas na Fig. 4. A amostra do óxido recém preparado possui uma capacidade específica de 202 e 180 mA.h.g ${ }^{-1}$ para carga e descarga, respectivamente. Entretanto o desempenho da amostra diminui drasticamente após ser estocada por 6 meses em exposição ao ar. As capacidades específicas apresentadas são de 167 e 142 mA.h.g ${ }^{-1}$ para carga e descarga, respectivamente. Tais resultados sugerem que o decréscimo do desempenho dos materiais estocados pode ser ocasionado por reações entre o $\mathrm{LiNi}_{0,4} \mathrm{Co}_{0,2} \mathrm{O}_{2}$ e a atmosfera, as quais incluem adsorção física/química e a possibilidade de reações redox diretas entre o material e os componentes da atmosfera.

$\mathrm{O} \mathrm{LiMn} \mathrm{O}_{4}$ com estrutura espinélio têm-se mostrado um material catódico promissor devido as suas propriedades bastante satisfatórias. Este material apresenta vantagens como baixa toxicidade, baixo custo e maior facilidade de processamento. Entretanto, a perda de capacidade durante consecutivos processos de carga e descarga (ciclagem), devido, principalmente, às distorções Jahn-Teller do manganês, torna necessária a otimização deste material, principalmente com relação à estabilidade eletroquímica [5]. Os detalhes de cristalinidade, estrutura, desvio da composição 


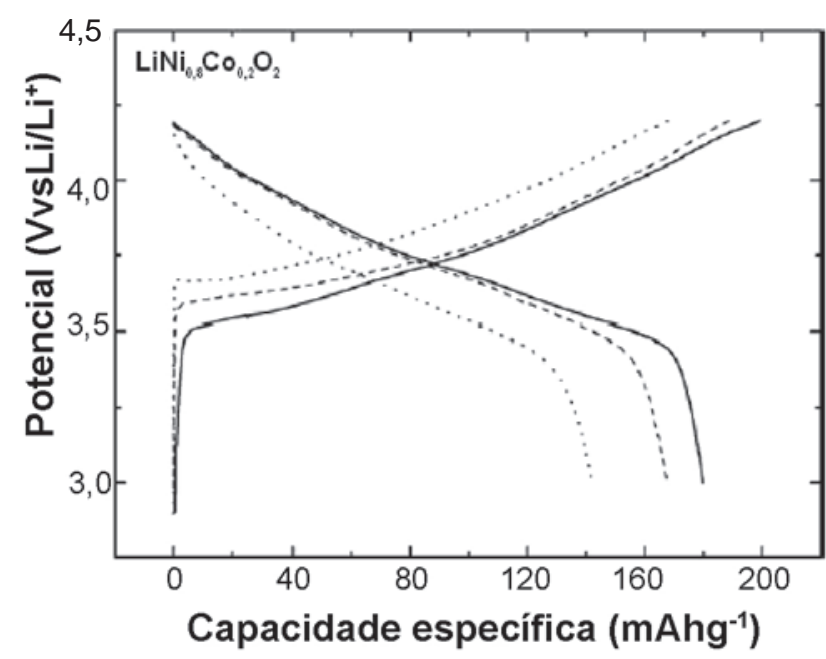

Figura 4: Curvas de carga/descarga do material catódico $\mathrm{LiNi}_{0,8} \mathrm{Co}_{0,2} \mathrm{O}_{2}$ : linha sólida, amostra recém preparada; linha tracejada, amostra estocada em argônio; linha pontilhada, amostra estocada em ar [39].

[Figure 4: $\mathrm{LiNi}_{0.8} \mathrm{Co}_{0.2} \mathrm{O}_{2}$ charge/discharge curves: (solid line) sample as-prepared; (dashed line) sample previously treated in argon atmosphere; (dotted line) sample submitted to ambient atmosphere [39].]

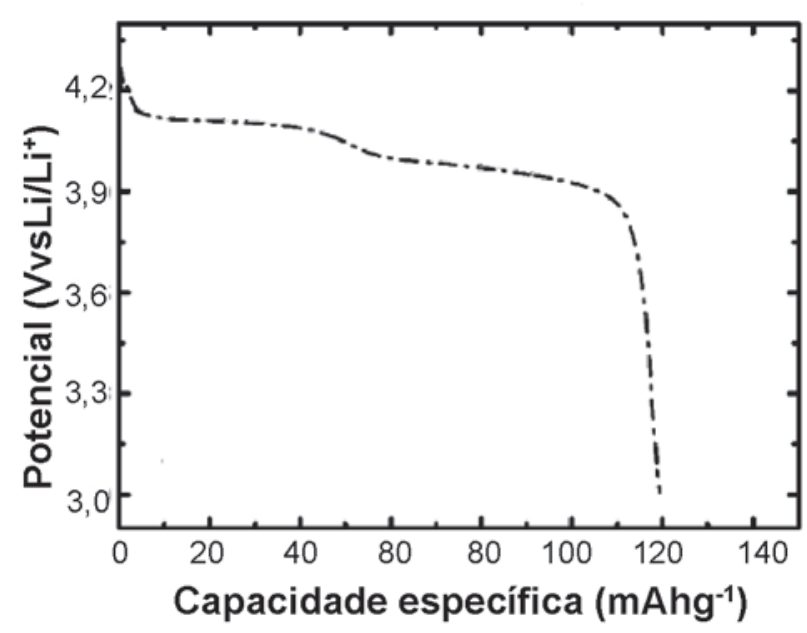

Figura 5: Curva de descarga da amostra de $\mathrm{LiMn}_{2} \mathrm{O}_{4}$ calcinado a $800{ }^{\circ} \mathrm{C}$ por $2 \mathrm{~h} \mathrm{[40].}$

[Figure 5: Discharge curve of $\mathrm{LiMn}_{2} \mathrm{O}_{4}$ calcined at $800{ }^{\circ} \mathrm{C}$ for $2 h$ [40].]

estequiométrica teórica, o tamanho de grão e a distribuição destes, possuem papel importante e, eventualmente decisivo no desempenho eletroquímico do óxido. A maioria de tais parâmetros é designada, ou pelo menos influenciada pelo processo de síntese. Luo et alii [40] estudaram o óxido $\mathrm{LiMn}_{2} \mathrm{O}_{4}$ calcinada a $800{ }^{\circ} \mathrm{C}$ por $2 \mathrm{~h}$. A curva de descarga desta amostra está apresentada na Fig. 5. O óxido sintetizado possui partículas com tamanho entre $300-400 \mathrm{~nm}$. A capacidade específica deste óxido, determinada por medidas de carga/descarga, foi, inicialmente 120 mA.h.g g $^{-1}$, sendo que após 100 ciclos o material ainda apresentava uma capacidade de, aproximadamente $95 \mathrm{~mA} . \mathrm{h} . \mathrm{g}^{-1}$, o que representa uma retenção de $79 \%$ de sua capacidade inicial [40]. Santiago et alii [5] também estudaram o desempenho eletroquímico do óxido $\mathrm{LiMn}_{2} \mathrm{O}_{4}$ obtido por combustão. Tal óxido foi aquecido a $800{ }^{\circ} \mathrm{C}$ por $4 \mathrm{~h}$, e a curva de carga/descarga apresentou uma capacidade eletroquímica de $107 \mathrm{~mA} . \mathrm{h} \cdot \mathrm{g}^{-1}$.

$\mathrm{O} \mathrm{LiCoO}_{2}$, embora apresente a desvantagem do alto custo relacionado ao cobalto, o alto desempenho e propriedades eletroquímicas favoráveis tornam este material o mais promissor para a aplicação em baterias de íons lítio até a atualidade. O bom funcionamento desse catodo se deve em grande parte, a perfeita bidimensionalidade de sua estrutura e à estabilidade da mesma durante os numerosos ciclos de carga e descarga a que são submetidas às baterias recarregáveis. Entretanto sua capacidade específica, na prática, é de $140 \mathrm{~mA} . h . \mathrm{g}^{-1}$, a qual corresponde somente a metade de sua capacidade específica teórica, $274 \mathrm{~mA} . \mathrm{h} . \mathrm{g}^{-1}$. Uma maior capacidade pode ser obtida carregando-se o material a potenciais mais altos (> 4,2 Vvs. $\left.\mathrm{Li}^{+} / \mathrm{Li}\right)$, contudo tais potenciais levam a uma severa deterioração estrutural, devido a transições de fase irreversíveis e a decomposição do eletrólito como consequiência da formação de oxigênio fortemente oxidante em estados altamente delitiados [41]. Santiago et alii [42] sintetizaram o óxido lamelar $\mathrm{LiCoO}_{2}$ por meio de duas metodologias de síntese distintas, método dos precursores poliméricos e combustão. A curva de descarga para ambos os materiais estão apresentadas na Fig. 6. A capacidade específica desenvolvida pelos óxidos é muito semelhante e próxima de $137 \mathrm{~mA} \cdot \mathrm{h}_{\mathrm{g}} \mathrm{g}^{-1}$, independente da metodologia de síntese utilizada. A química de superfície apresenta grande relevância no desempenho do eletrodo. Descobriuse que uma modificação na superfície pode ocasionar uma melhora na estabilidade estrutural e térmica assim como no desempenho eletroquímico do $\mathrm{LiCoO}_{2}$. Estas mudanças foram atribuídas à formação de uma solução sólida homogênea na superfície das partículas de $\mathrm{LiCoO}_{2}$. Estudos recentes mostraram que revestindo as partículas de $\mathrm{LiCoO}_{2}$ com óxidos tais como $\mathrm{Al}_{2} \mathrm{O}_{3}, \mathrm{MgO}, \mathrm{ZrO}_{2}, \mathrm{TiO}_{2}, \mathrm{SnO}_{2}, \mathrm{CeO}_{2}$, $\mathrm{ZnO}, \mathrm{P}_{2} \mathrm{O}_{5}$ e $\mathrm{SiO}_{2}$ ajuda a reprimir a perda de capacidade em altos estados de carga [41]. Resultados obtidos por Bai et alii [41], por outro lado, indicaram que até mesmo um revestimento compacto não é capaz de prevenir a corrosão do $\mathrm{LiCoO}_{2}$ por um eletrólito ácido. O revestimento das superfícies aumenta a acidez do eletrólito pela formação do ácido de Lewis por meio da interação com o eletrólito [41]. Bai et alii [41] sintetizaram o óxido $\mathrm{LiCoO}_{2}$ com $\mathrm{MgCl}_{2}$ fundido, o que proporcionou um revestimento de $\mathrm{MgO}$ ao óxido obtido. Com a formação de tal revestimento esperava-se obter um material com um melhor desempenho eletroquímico. Um óxido comercial, calcinado a $750^{\circ} \mathrm{C}$, foi testado e apresentou uma capacidade específica inicial de 131 mA.h.g ${ }^{-1}$ e uma capacidade de retenção, após 60 ciclos, de $84 \%$. Por outro lado, o mesmo óxido comercial de $\mathrm{LiCoO}_{2}$ tratado com $10 \% \mathrm{MgCl}_{2}$ demonstrou desempenho um pouco melhor, sendo que sua capacidade específica inicial foi de 166 mA.h.g ${ }^{-1}$ e a capacidade de retenção $91 \%$ após 60 ciclos 

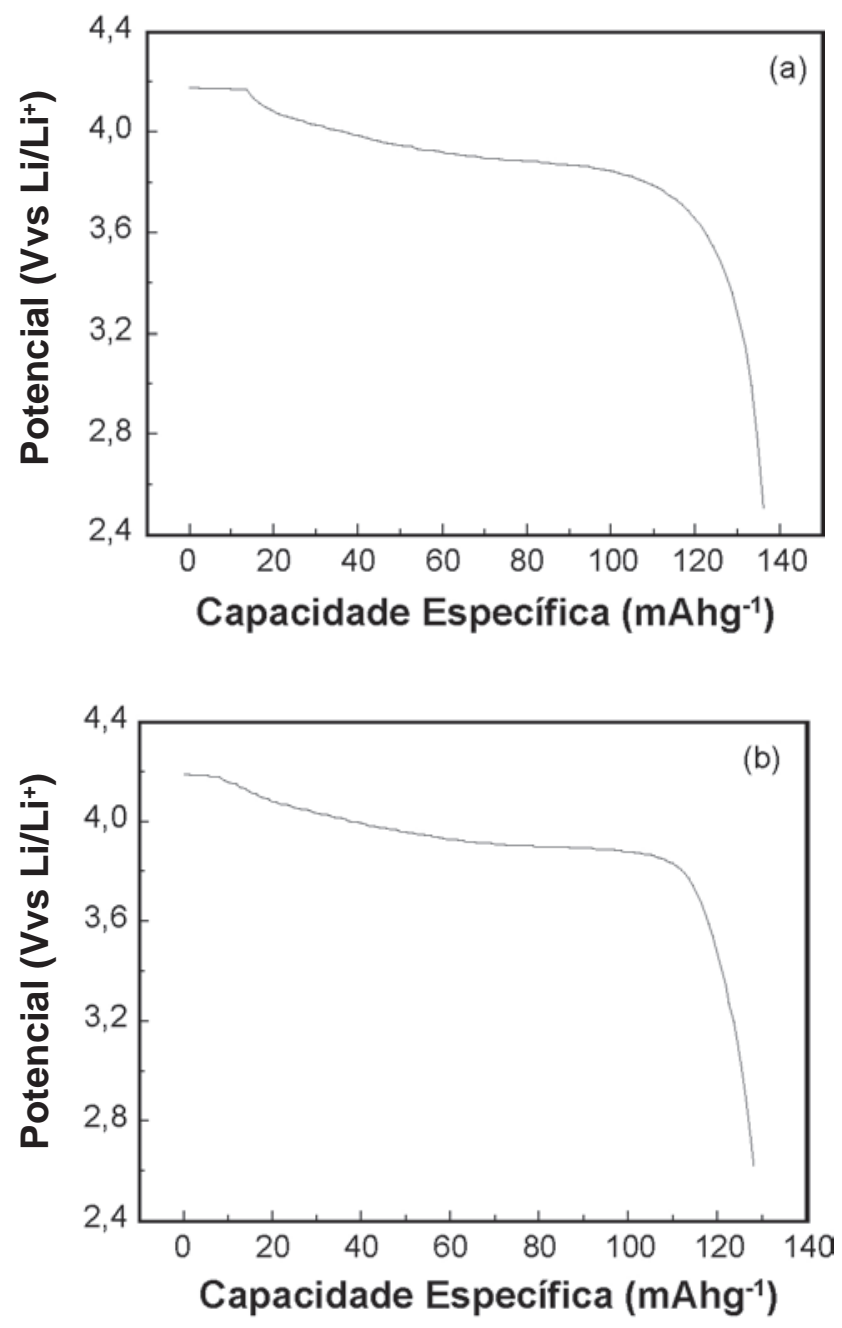

Figura 6: Curvas de descarga para $\mathrm{LiCoO}_{2}$ sintetizado por combustão (a) e pelo método dos precursores poliméricos (b) [42]. [Figure 6: (a) Discharge curves of LiCoO ${ }_{2}$ synthesized by combustion reaction and (b) by polymeric precursors method [42].]

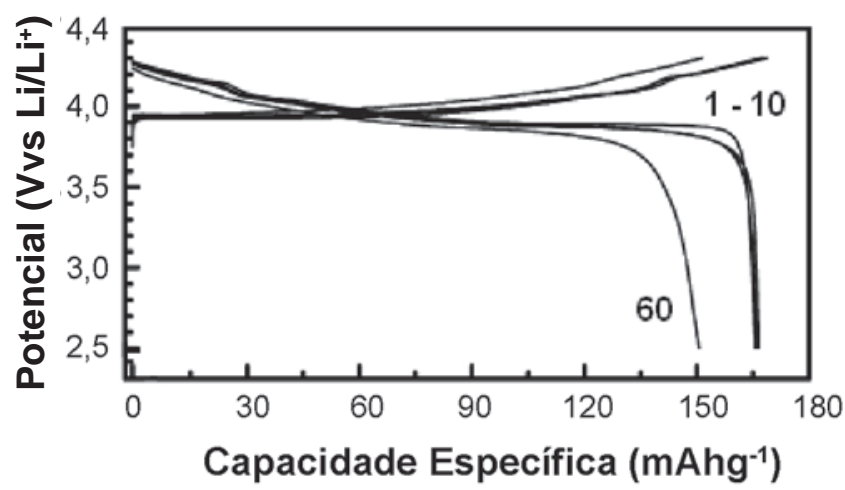

Figura 7: Curvas de carga/descarga obtidas com o óxido de $\mathrm{LiCoO}_{2}$ superficialmente revestido com $\mathrm{MgO}$, a partir de uma mistura de $10 \%$ de $\mathrm{MgCl}_{2}[41]$.

[Figure 7: Charge/discharge curves of LiCoO ${ }_{2}$ superficially coated with $\mathrm{MgO}$, from a mixture of $10 \% \mathrm{MgCl}_{2}$ [41].] de carga/descarga. Estes resultados indicam uma melhora na reversibilidade estrutural na superfície modificada do óxido $\mathrm{LiCoO}_{2}$ em estados altamente delitiados. Entretanto, um excesso na adição de $\mathrm{MgCl}_{2}$ causa a diminuição de sua capacidade e a deterioração da reversibilidade do material, o que pode ser observado na Fig. 7 [41].

\section{Materiais anódicos}

Até a década de 80 o lítio metálico e suas ligas metálicas eram utilizados como materiais anódicos em combinação com vários materiais catódicos em baterias de íons lítio [4]. O lítio metálico é o material mais atraente para o uso como anodo em baterias recarregáveis devido ao seu potencial (-3,045 V vs. eletrodo padrão de hidrogênio) e sua alta capacidade específica (3860 mA.h.g ( $\left.^{-1}\right)$ [43, 44]. Por mais de duas décadas o lítio metálico foi largamente utilizado como anodo em células primárias de lítio. Entretanto, quando as baterias são submetidas a ciclos prolongados de deposição/ dissolução em eletrólitos líquidos ocorre uma blindagem do lítio com simultânea corrosão e passivação (formação de uma interface de eletrólito sólido). O lítio, geralmente, se deposita como dendrito, partículas de metal altamente reativo. Os dendritos são cobertos com uma interface de eletrólito sólido e por esta razão tornam-se parcial e eletroquimicamente inativos, o que reduz a ciclabilidade da célula. Além disso, os dendritos podem formar filamentos que curto-circuitam a célula localmente. Devido ao baixo ponto de fusão do lítio, um superaquecimento local pode levar a uma desastrosa trânsfuga térmica [3]. Com o objetivo de superar tais desvantagens muitos materiais de inserção de íons lítio têm sido propostos para atuar como anodos em baterias recarregáveis de íons lítio, grafite e óxido de estanho são alguns exemplos. A Tabela II mostra a capacidade específica e a densidade de carga teórica para alguns materiais de inserção utilizados como anodos.

A partir de 1985, a única alternativa aos anodos de lítio metálico, adotada para contornar problemas de segurança, foram os materiais de intercalação de íons lítio baseados em carbono, os quais introduziram o conceito de baterias recarregáveis do tipo "rocking-chair" [4]. Recentes desenvolvimentos em baterias recarregáveis de íons lítio também foram alcançados com o uso de anodos de carbono como reservatório de lítio. Os íons lítio podem ser intercalados na maioria dos compostos de carbono, sendo que o composto litiado resultante possui um potencial eletroquímico negativo próximo ao apresentado pelo eletrodo de lítio metálico. As reações reversíveis de intercalação/desintercalação resolvem o problema de formação dendrítica do lítio e provocam melhoras na segurança e ciclabilidade.

Grafite é o anodo mais comumente usado em baterias secundárias de íons lítio. A boa estabilidade durante os ciclos de carga/descarga é um dos critérios mais importantes para a confiabilidade e a longa vida da bateria. É comumente aceito que a composição e a estrutura de passivação do filme de interface de eletrólito sólido são críticos para a estabilidade cíclica da bateria. Este filme resulta dos produtos de redução 
Tabela II - Características de materiais anódicos usados em baterias de íons lítio [3].

[Table II - Characteristics of the anodic materials used in ions lithium batteries [3].]

\begin{tabular}{cccc}
\hline $\begin{array}{c}\text { Material } \\
\text { anódico }\end{array}$ & $\begin{array}{c}\text { Massa } \\
\text { molecular } \\
(\mathrm{g})\end{array}$ & $\begin{array}{c}\text { Capacidade } \\
\text { específica } \\
\left(\mathrm{AhKg}^{-1}\right)\end{array}$ & $\begin{array}{c}\text { Densidade } \\
\text { de carga } \\
\left(\mathrm{AhL}^{-1}\right)\end{array}$ \\
\hline $\mathrm{Li}^{0}$ & 6,94 & 3862 & 2047 \\
$\mathrm{LiC}_{6}($ grafite $)$ & 79,00 & 372 & 759 \\
$\mathrm{SnO}_{2}$ & 150,69 & 600 & \\
\hline
\end{tabular}

e decomposição do solvente, começando durante o primeiro processo de carga. Este filme, cobrindo a superfície do grafite exposta ao eletrólito deve ser permeável aos íons lítio e eletronicamente isolante de modo a prevenir uma decomposição adicional do eletrólito durante os ciclos de carga/descarga. Entretanto um crescimento adicional da interface de eletrólito sólido causará uma redução da condutividade do grafite e de sua capacidade de reversibilidade [45].

Recentes desenvolvimentos em baterias recarregáveis de íons lítio foram alcançados pelo uso de materiais carbonáceos como reservatório de lítio em anodos. As reações de carga e descarga são descritas simplesmente como expresso pela Equação F.

$$
\mathrm{Li}_{\mathrm{y}} \mathrm{C}_{6} \leftrightarrow \mathrm{C}_{6(\mathrm{~s})}+\mathrm{yLi}^{+}{ }_{(\text {solv })}+\mathrm{ye}^{-}
$$

Os íons lítio podem ser intercalados na maioria dos tipos de material carbonáceo, e o material litiado resultante apresenta um potencial eletroquímico extremamente negativo e próximo ao potencial do eletrodo de lítio metálico [46]. As propriedades eletroquímicas de intercalação de lítio dos compostos de carbono dependem da cristalinidade, morfologia e orientação dos cristais. Muitos tipos de compostos de carbono, desde cristalinos até fortemente desorientados, têm sido testados como anodos em baterias de íons lítio na última década. Como resultado, grafite é atualmente, o composto de carbono mais amplamente utilizado como anodo em baterias de lítio comercialmente disponíveis, devido a sua capacidade específica relativamente alta (teoricamente $372 \mathrm{~mA} . \mathrm{h}^{-1}$ ), baixa capacidade de irreversibilidade e boa ciclabilidade [46]. Entretanto, o rápido desenvolvimento dos dispositivos eletrônicos atuais demanda aos anodos de carbono uma densidade de energia muito maior, assim como uma maior densidade de energia e uma capacidade irreversível ainda menor.

Sun et alii [34] sintetizaram um compósito de carbono com lítio metálico a partir de carbono comercial. O desempenho eletroquímico do compósito e do grafite comercial foram comparados. A Fig. 8a mostra a curva de carga/descarga do eletrodo de carbono no primeiro ciclo. As curvas apresentam um declínio de potencial apreciável,
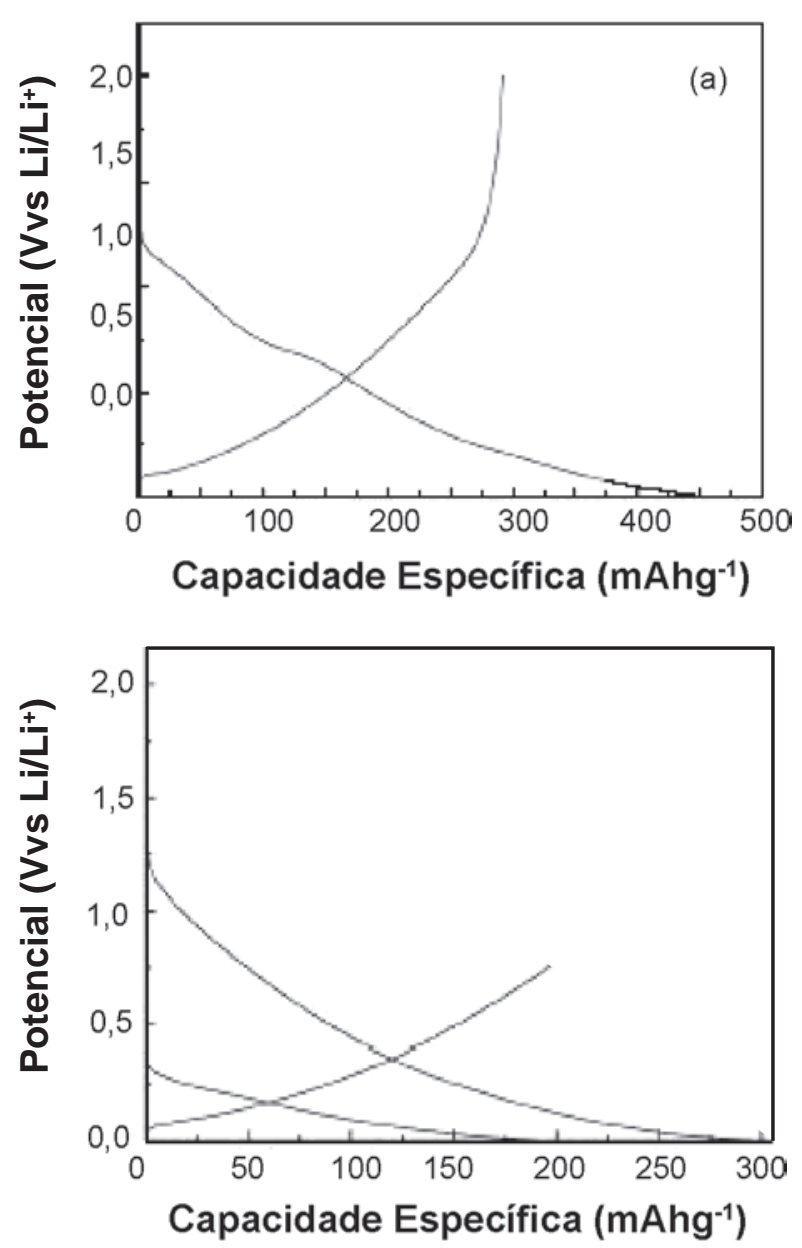

Figura 8: Curvas de carga/descarga: (a) anodo de carbono; (b) anodo de compósito de carbono/lítio (94:6) vs. lítio metálico, ambos no primeiro ciclo [34].

[Figure 8: Charge/discharge curves: (a) carbon anode; (b) composite carbon/lithium (94:6) anode vs. metallic lithium, both in the first cycle [34].]

sendo esta a única vantagem de tal material, o qual possui uma eficiência coulômbica de 66\%. O compósito de carbono e lítio foi desenvolvido com o intuito de eliminar a capacidade irreversível inicial do carbono, a qual se acredita estar relacionada ao processo de aprisionamento de lítio nos micro poros do material. A Fig. 8b apresenta as curvas de carga/descarga do eletrodo formado pelo compósito carbono/lítio (94:6). A primeira capacidade de inserção de lítio (194 mA.h.g g $^{-1}$, 65\% da capacidade total), isto, devido ao lítio metálico pressionado com o carbono, o qual oferece lítio adicional para ser inserido no processo de descarga. Por outro lado o processo de extração de lítio é o mesmo para os dois eletrodos, e quando comparado com o carbono, o compósito não apresenta capacidade irreversível inicial. A eficiência coulômbica do eletrodo compósito permanece aproximadamente $100 \%$ sobre os processos de carga/ descarga. Após o teste inicial a célula foi desmontada dentro de uma caixa seca, preenchida com argônio, e nenhum resíduo 
do lítio metálico na superfície do eletrodo foi encontrado. O lítio metálico foi, portanto, totalmente utilizado, o que faz com que tal célula apresente baixo risco [34].

Recentemente, as baterias secundárias de íons lítio, tendo grafite como anodo, tornaram-se rapidamente importantes para o uso em uma variedade de dispositivos eletrônicos. Apesar da sua comercialização bem sucedida, vários materiais anódicos novos tem sido investigados para contornar a limitada capacidade específica do grafite (372 mA.h.g $\mathrm{g}^{-1}$ ), a qual é menor do que um décimo da capacidade do lítio metálico (3680 mA.h.g ${ }^{-1}$ ). O mundo inteiro tem se esforçado na pesquisa de materiais anódicos alternativos para substituir o grafite no uso como material anódico em baterias de íons lítio. Materiais baseados em óxido de estanho, tais como, $\mathrm{SnO}_{2}$ e $\mathrm{SnO}$ apresentaram uma capacidade específica maior como material anódico ativo do que os materiais carbonáceos [47].

Entretanto, uma grande perda irreversível na capacidade durante o primeiro ciclo, devido à reação de redução/ reposição impede que o óxido de estanho possa ser aplicado como material catódico. Também foi reportado que os óxidos de estanho são reduzidos durante a primeira descarga formando partículas finas de estanho e uma fase inativa, como $\mathrm{Li}_{2} \mathrm{O}$, a qual reduz o crescimento do estanho. Devido a redução do $\mathrm{SnO}$, os anodos de óxido de estanho necessitam, para compensar, um excesso de material catódico para serem usados. Nanocompósitos compreendendo constituintes ativos e inativos com lítio podem ser uma maneira de resolver o problema.

Idota et alii sintetizaram um compósito de óxido de metal amorfo, apresentado na Fig. 9, o qual é representado pela fórmula $\mathrm{SnM}_{\mathrm{x}} \mathrm{O}_{\mathrm{y}}$ (onde M é uma mistura de $\mathrm{B}(\mathrm{III}), \mathrm{P}(\mathrm{V})$ e $\mathrm{Al}(\mathrm{III})$ ), capaz de estocar íons lítio com uma capacidade Coulômbica próxima às ligas de estocagem de hidrogênio, garantindo proteção contra a formação dentrítica de Li. Tal material amorfo é um compósito de óxido vitrificado que contém óxido de estanho (II) como centro ativo para a

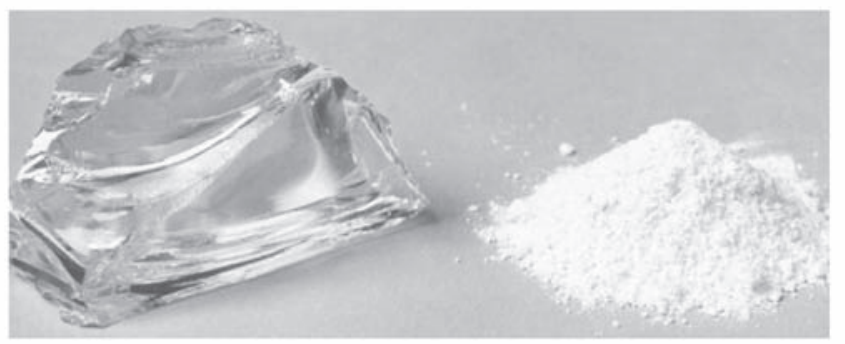

Figura 9: Compósito baseado em óxido de estanho (à esquerda). Vidro amarelo e transparente com densidade de $3,7 \mathrm{~g} / \mathrm{cm}^{3}$. Triturado produz um pó branco de material ativo (à direita) capaz de inserir íons lítio quando utilizado como anodo em baterias recarregáveis [4].

[Figure 9: Tin oxide-based composite as active material (left). It is a yellowish transparent glass with a density of $3.7 \mathrm{~g} / \mathrm{cm}^{3}$. Crushing the glass provides a white powder of active material (right) capable to be used as Li insertion negative electrode of Li-ion rechargeable battery device [4].] inserção de lítio [4].

$\mathrm{Na}$ estrutura do óxido, o estanho (II) forma o centro eletroquimicamente ativo para a inserção de íons lítio, e o outro grupo de metais produz uma rede eletroquimicamente inativa de ligações -(M-O)-, a qual deslocaliza o centro ativo de estanho (II).

Uma célula de transferência de íons lítio Stalion anunciada em meados da década de 90 pela Fujifilm Celltech Co. Ltd. utiliza o compósito baseado em óxido de estanho amorfo como anodo. Tal material anódico combina uma ciclabilidade promissora e uma alta capacidade específica (600 mA.h.g $\left.{ }^{-1}\right)$ e densidade de carga (2200 A.h/L $\left./ \mathrm{L}^{-1}\right)$. Este anodo é sintetizado a partir de $\mathrm{SnO}, \mathrm{B}_{2} \mathrm{O}_{3}, \mathrm{Sn}_{2} \mathrm{P}_{2} \mathrm{O}_{7}, \mathrm{Al}_{2} \mathrm{O}_{3}$, e outros precursores. Entretanto, somente os compostos de estanho (II), em tal compósito de óxido, é dito formar os centros eletroquimicamente ativos para a inserção de lítio [3].

\section{O PAPEL DAS NANOESTRUTURAS NO DESEM- PENHO DAS BATERIAS DE ÍONS LÍTIO}

Recentemente, sistemas recarregáveis de íons lítio têm-se tornado uma tecnologia proeminente no mercado de baterias global, pois estas oferecem a maior densidade de energia disponível da época para baterias recarregáveis. Enquanto que as baterias de íons lítio produzidas atualmente governam a maioria dos pequenos dispositivos, tais como, aparelhos celulares, computadores portáteis e equipamentos eletroópticos móveis, esforço mundial intensivo tem sido feito para impulsionar a tecnologia muito além das pretendidas aplicações, tais como baterias de maiores capacidades, menor volume e de maior rapidez na entrega de potência para veículos elétricos [48].

Materiais em micro-escala geralmente exibem as mesmas propriedades que quando em "bulk". Entretanto, materiais nanométricos (ou nano-escala) podem exibir propriedades físicas consideravelmente diferentes daquelas em "bulk". A nanotecnologia envolve a fabricação, caracterização e manipulação de materiais com dimensão no intervalo de $1 \mathrm{a}$ 100 nanômetros [49].

Do ponto de vista da ciência de materiais e superfície, muitas propriedades de sistemas são controladas pelas interfaces e contato entre diferentes materiais [50]. As interfaces em materiais policristalinos microestruturados são consideradas defeitos que influenciam nas propriedades macroscópicas. Em materiais policristalinos nanoestruturados, por outro lado, a interface predomina e o "bulk" possui um papel totalmente diferente [49].

Os dispositivos de armazenamento e conversão de energia eletroquímica formam um importante ramo da energia alternativa emergente no século XXI [51] que, assim como a nanotecnologia, possui implicações científicas, tecnológicas e políticas fundamentais.

Nos últimos anos, o uso de nanomateriais em catodos de inserção de íons lítio ao invés de materiais convencionais tem se tornado muito atraente para melhorar o desempenho 
das baterias recarregáveis de lítio. Muitos grupos vêm mostrando que materiais nanométricos vêm emergindo como soluções bem sucedidas para aumentar a capacidade padrão e a estabilidade cíclica destes eletrodos.

No campo emergente da nanotecnologia aplicada ao projeto de eletrodos, o objetivo é criar nanoestruturas com propriedades especiais diferentes daquelas do "bulk" ou de nanopartículas individuais. A inter-relação entre a eletroquímica de superfície e a nanociência permite o surgimento de novas possibilidades para desenhar uma superfície química, controlando sua estrutura em nível molecular, e conduzindo a superfícies metálicas ou semicondutoras inovadoras [49]. Particularmente, estes eletrodos nanoestruturados apresentam uma capacidade padrão melhor do que os eletrodos convencionais compostos dos mesmos materiais [52]. Em partículas nanoscópicas a acomodação da carga ocorre principalmente na superfície ou muito próxima dela, portanto quanto menor as partículas, maior a porção de tais átomos constituintes na superfície. Este fato reduz a necessidade da difusão de íons lítio na fase sólida, aumentando de maneira considerável a velocidade de carga/descarga do catodo, principalmente por fornecer um recurso para a difusão muito melhor do que os necessários em escala micrométrica. Com isso ocorrerá também uma redução nas mudanças volumétricas e estresse estrutural causados pelos repetidos processos de inserção e desinserção de íons lítio do material [30].

Quando consideramos eletrodos compostos por materiais eletroativos nanométricos, uma alta densidade de energia e uma alta densidade de potência (o mesmo que capacidade padrão) devem ser, simultaneamente, concluídos, o que requer uma grande área interfacial eletrodo-eletrólito, juntamente com pequenas distâncias de difusão nos eletrodos. Materiais nanométricos para dispositivos de estocagem de íons lítio têm emergido como uma solução bem sucedida para melhorar a capacidade específica e a cinética de carregamento e a potência de descarga. Durante os pulsos de alta potência requeridos para a transmissão de informações de voz comprimida e digitadas, a capacidade de transferência da bateria diminui a uma fração de seu valor específico. Acredita-se que estas limitações na capacidade específicas das baterias de íons lítio são causadas pela lenta difusão dos íons lítio em materiais eletródicos no estado sólido. Por esta razão, atualmente, grande interesse tem sido focado na pesquisa e desenvolvimento de eletrodos nanoestruturados para baterias de íons lítio, cuja nanoestrutura, claramente, restringe a distância que os íons lítio devem difundir, a qual deve ser aproximadamente $50 \mathrm{~nm}$. Dois tipos de geometria são comumente aplicados para se conseguir uma difusão em estado sólido mais rápida, como apresentada na Fig. 10. A primeira geometria é baseada em nanopartículas esféricas conectadas enquanto que a segunda é baseada em nanofibras alongadas, como uma escova, a partir do coletor de corrente; na verdade este tipo de geometria para eletrodo nanoestruturado permite uma melhora na capacidade específica. O uso de materiais nanoestruturados para

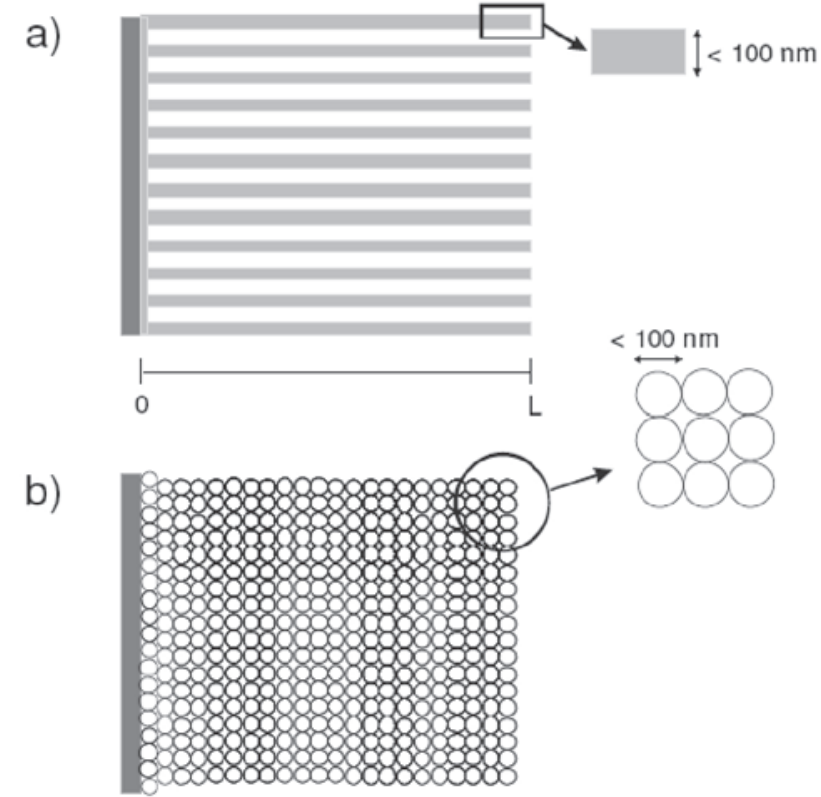

Figura 10: Representação esquemática de um eletrodo nanoestruturado altamente poroso alongado a partir de um coletor de corrente. (a) Estrutura de uma nanofibra ou uma lâmina tipo membrana, e (b) nanoestrutura baseada em partículas do tipo esféricas. Note que nanoestruturas reais não são tão regulares, mas ambos, a fase nanoestruturada e o eletrólito, são contínuos ao longo de um comprimento $L$. O comprimento $L$ determina se o eletrodo nanoestruturado será considerado 2-D ou 3-D, o que é muito importante para modelar o transporte iônico e eletrônico no eletrodo nanoestruturado [49].

[Figure 10: Schematic representation of a highly porous nanostructured electrode protruding from a current collector. (a) Nanofiber structure or a template-like membrane, and (b) sphericallike particle-based nanostructure. Note that real nanostructures are not so regular, but both nanostructured phase and electrolyte, as discussed herein, are continuous along the length $L$. The length $L$ determines if the nanostructured electrode will be considered 2$D$ or 3-D and is very important in modeling electronic and ionic transport in the nanostructured electrode [49].]

baterias não está restrito às baterias de íons lítio. Materiais nanocristalinos híbridos de metais e níquel também têm sido desenvolvidos, e os materiais nanoestruturados oferecem melhoras em termos de densidade de potência e durabilidade, controlando-se a difusão de carga e o estado de oxidação em nível nanométrico [49].

Nanopartículas possuem raios de nucleação crítica maiores que o diâmetro da partícula. Transições estruturais para estruturas termodinamicamente indesejadas podem ocorrer somente se o raio da partícula for maior do que o raio de nucleação crítica para tal fase, sendo possível eliminar tais transições utilizando-se nanopartículas com raios de nucleação crítica maiores que o raio da partícula. Portanto, pequenas partículas acomodariam mais facilmente as mudanças estruturais que ocorrem durante os processos de inserção e extração de íons lítio, ou seja, carga/descarga da bateria. 
As células de íons lítio disponíveis comercialmente, as quais são as mais avançadas entre as baterias recarregáveis disponíveis até agora, empregam óxidos de metais de transição microcristalinos como catodos, os quais funcionam como matrizes de inserção de lítio. Diversos grupos vêm mostrando, atualmente, que os nanomateriais estão emergindo como soluções bem sucedidas para aumentar a capacidade padrão e a estabilidade cíclica de tais eletrodos [30], além da cinética de inserção/deinserção e, conseqüentemente, de carregamento das baterias.

Todos os materiais catódicos de interesse para baterias de íons lítio reagem com as soluções eletrolíticas comumente utilizadas desenvolvendo uma superfície química rica. Consequentemente, o comportamento eletroquímico da maioria dos materiais catódicos depende fortemente da química de sua superfície em solução e de fenômenos, tais como, a formação do filme superficial [48].

Em contraste com a precisão que pode ser alcançada na análise de "bulk" dos materiais catódicos, a análise rigorosa da sua superfície é muito mais complicada, devido à formação de filmes superficiais muito finos, cuja composição e estrutura podem ser profundamente influenciadas por impurezas contidas na solução (até mesmo em concentrações a nível de ppm) [48].

Ye et alii [52] sintetizaram o óxido $\mathrm{LiMn}_{2} \mathrm{O}_{4}$ por reação de estado sólido promovida em moinho de bolas. Tal material foi submetido a um tratamento térmico a $500^{\circ} \mathrm{C}$, e neste material foram observados grãos com um tamanho médio de 20-30 $\mathrm{nm}$. Testou-se o desempenho eletroquímico deste óxido, o qual apresentou uma capacidade específica de descarga de aproximadamente $125 \mathrm{~mA} . \mathrm{h} . \mathrm{g}^{-1}$. Santiago et alii [5] também sintetizaram este óxido por meio de reação de combustão, e obtiveram um material com capacidade específica de descarga de 107 mA.h.g ${ }^{-1}$. O aumento da capacidade no nanomaterial pode ser atribuído a uma repulsão coulômbica $\mathrm{Li}^{+}-\mathrm{Li}^{+}$menor na superfície de materiais nanométricos, aumentando, desta maneira a capacidade local de Li devido a não ocorrência de íons lítio na vizinhança próxima da partícula [52].

Com respeito aos anodos, o principal objetivo é a substituião dos materiais baseados em carbono por materiais com capacidades específicas maiores, tais como, metais ou compostos que formam ligas com o lítio, por exemplo, Sn, $\mathrm{Si}, \mathrm{Sb}$, etc. [53].

Como possível anodo para a próxima geração de baterias de íons lítio, materiais baseados em óxido de estanho apresentam-se muito promissores, devido a sua alta capacidade de armazenamento [53]. Yuan et alii [53] estudaram o óxido de estanho, $\mathrm{SnO}_{2}$, sintetizado utilizandose a técnica de pulverização por pirólise. Em seguida o material obtido, $\mathrm{SnO}_{2}$, foi submetido a tratamentos térmicos diferenciados $\left(600,800,1000\right.$ e $\left.1200^{\circ} \mathrm{C}\right)$, sendo que uma porção do material foi testada sem tratamento. $\mathrm{O}$ tamanho dos cristais juntamente com sua retenção de capacidade é mostrado na Tabela III.

Todas as amostras foram submetidas a testes de carga/ descarga, e o $\mathrm{SnO}_{2}$ inicial, ou seja, sem nenhum tratamento térmico, apresentou uma excelente estabilidade cíclica, sendo que exibiu uma retenção de $68,2 \%$ da capacidade inicial (601 mA.h.g $\left.{ }^{-1}\right)$ após 50 ciclos (410 mA.h.g $\left.\mathrm{g}^{-1}\right)$. O exemplo deste trabalho ilustra bem o efeito do tamanho da partícula no desempenho eletroquímico dos materiais eletródicos de inserção de íons lítio, e mostra que conforme o tamanho das partículas diminui a estabilidade cíclica do material aumenta.

Tabela III - Tamanho dos cristais das amostras de $\mathrm{SnO}_{2}$ juntamente com as temperaturas de tratamento térmico e desempenho eletroquímico [53].

[Table III - Crystal size of the $\mathrm{SnO}_{2}$ samples accompanied by heat treat temperatures and electrochemical performance [53].]

\begin{tabular}{ccc}
\hline $\begin{array}{c}\text { Temperatura de } \\
\text { tratamento térmico }\left({ }^{\circ} \mathrm{C}\right)\end{array}$ & $\begin{array}{c}\text { Tamanho dos } \\
\text { cristais (nm) }\end{array}$ & $\begin{array}{c}\text { Retenção da } \\
\text { capacidade } \\
(\%)\end{array}$ \\
\hline $\begin{array}{c}\text { Inicial } \\
\text { (sem tratamento) }\end{array}$ & 5,1 & 68,2 \\
600 & 12,92 & 54,6 \\
800 & 32,97 & 51,6 \\
1000 & 53,86 & 36,7 \\
1200 & 101,01 & 18,5 \\
\hline
\end{tabular}

\section{CONCLUSÕES}

Os dispositivos de armazenamento de energia são de vital importância para a vida na sociedade atual, e as baterias recarregáveis de íons lítio ocupam um lugar significante no mercado de fontes de energia móvel. Esta área vem alcançando um alto progresso com o surgimento de dispositivos com uma maior capacidade de armazenamento de carga em volumes, a cada dia, menores. Contribuindo para tal progresso encontram-se os eletrodos, catodo e anodo, compostos por materiais cerâmicos de inserção, especialmente nanoestruturados, os quais acumulam as vantagens de uma alta densidade de carga armazenada em um menor volume. Como visto, materiais nanoestruturados também têm contribuído para atenuar os problemas da lenta difusão dos íons lítio, pois a distância que os íons precisam percorrer em nanoestruturas é limitada pelo raio da partícula. $\mathrm{O}$ alto estresse estrutural também tem sido evitado pelo uso de nanoestruturas, visto que o mesmo pode ser minimizado pela acomodação da carga, sendo que esta ocorre principalmente na superfície das nanopartículas.

\section{REFERÊNCIAS}

[1] N. Bocchi, L. C. Ferracin, S. R. Biaggio, Química e Sociedade 11 (2000) 3.

[2] J. M. Tarascon, M. Armand, Nature 414, 6861 (2001) 359.

[3] M. Winter, J. O. Besenhard, M. E. Spahr, P. Novak, Adv. 
Mater. 10, 10 (1998) 725.

[4] Y. Idota, T. Kubota, A. Matsufuji, Y. Maekawa, T. Miyasaka, Science 276, 5317 (1997) 1395.

[5] E. I. Santiago, S. T. Amancio, P. R. Bueno, L. O. S. Bulhoes, J. Power Sources 97-8, (2001) 447.

[6] J. Cristian, Gholam, N., Solid State Batteries: Materials Design and Optimization, Kluwer, Boston (1994).

[7] J. Cristian, Stoyanov, Z., Materials for lithium batteries, Kluwer, Boston (2000).

[8] G. Pistoia, Lithium Batteries: Science and Tecnology, Gholam-Abbas, New York (2003).

[9] C. Julien, Solid State Ionics 136, (2000) 887.

[10] G. Schalkwijk, Advances in Lithium-Ion Batteries, Springer Press, New York (2002).

[11] W. Müller-Warmuth, R. Schöllhorn, R., Physics and Chemistry of Materials with Low-Dimensional Structures, Academic Press, London (2002).

[12] A. R. West, Solid State Chemistry and its Applications, John Wiley \& Sons, New York (1998).

[13] R. Zboril, M. Mashlan, D. Petridis, Chemistry of Materials, John Wiley \& Sons, New York (2002).

[14] M. S. Whittingham, Chem. Rev. 104, 10 (2004) 4271.

[15] H. Liu, Y. P. Wu, E. Rahm, R. Holze, H. Q. Wu, J. Solid State Electrochem. 8, 7 (2004) 450.

[16] K. Brandt, Solid State Ionics 69, (1994) 173.

[17] T. Ohzuku, A. Ueda, Solid State Ionics 69, (1994) 201.

[18] M. M. Thackeray, J. Electrochem. Soc. 142, 8 (1995) 2558.

[19] A. M. E. Skudin, O. G. V. Yarmolenko, Russ. Chem. Ver. 71, 4 (2002) 329.

[20] P. Gomez-Romero, Adv. Mater. 13, 3 (2001) 163.

[21] P. Gomez-Romero, Adv. Mater. 13, 3 (2001) 163.

[22] Y. Mosqueda, E. Perez-Cappe, P. Aranda, E. RuizHitzky, Eur. J. Inorg. Chem. 13 (2005) 2698.

[23] H. Kawaoka, L. Chen, Z. Wu, Y. Liang, J. Electrochem. Solid-State Lett. 2, 11 (1999) 547.

[25] M. G. Kanatzidis, C. -G. Wu, H. O. Marcy, C. R. Kannewurf, J. Am. Chem. Soc. 111, (1989) 4139.

[26] F. Leroux, B. E. Koene, L. F. Nazar, J. Electrochem. Soc. 143, 9 (1996) L181.

[27] J.-B. Jung, C. -H. Lee, J. -W. Kim, K. -D. Suh, J. Polym. Sci.: Part B: Polym. Phys. 40 (2002) 1163.
[28] R. V. Kumar, Y. Mastai, Y. Diamant, A. Gedanken, J. Mater. Chem. 11, 4 (2001) 1209.

[29] C. P. Fonseca, S. Neves, J. Power Sources 135, 1-2 (2004) 249.

[30] F. F. C. T. Bazito, R. M., J. Braz. Chem. Soc. 17, 4 (2006) 627.

[31] G. T. K. Fey, V. Subramanian, C. Z. Lu, Solid State Ionics 152 (2002) 83.

[32] T. Nagaura, K. Tozawa, Prog. Batteries Solar Cells 9 (1990) 209.

[33] M. Y. Song, R. Lee, J. Power Sources 111, 1 (2002) 97.

[34] H. Sun, S. He, J. Ren, J. Li, C. Jiang, C. Wan, Electrochim. Acta 52 (2007) 4312.

[35] M. R. Palacin, D. Larcher, A. Audemer, N. S. Epee, G. G. Amatucci, J. M. Tarascon, J. Electrochem. Soc. 144 (1997) 4226.

[36] J. Maruta, H. Yasuda, M. Yamashi, J. Power Sources 90 (2000) 89.

[37] Y. Sun, P. Wan, J. Pan, C. Xu, X. Liu, Solid State Ionics 177 (2006) 1173.

[38] S. S. -R. Castro-Garcia, A. Castro-Couceiro, C. Julien, Cerámica y Vidrio 43, 4 (2004) 780.

[39] H. Liu, Y. Yang, J. Zhang, J. Power Sources 162 (2006) 644.

[40] J.-Y. Luo, X.-L. Xi, Y.-Y. Xia, Electrochim. Acta 52 (2007) 4525.

[41] Y. Bai, H. Chi, Z. Wang, L. Chen, J. Power Sources 167, 2 (2007) 504.

[42] E. I. Santiago, P. R. Bueno, A. V. C. Andrade, C. O. Paiva-Santos, L. O. S. Bulhoes, J. Power Sources 125, 1 (2004) 103.

[43] J. Yamaki, S. Tobishima, Handbook of Battery Materials (1999) 339.

[44] M. Inaba, Z. Ogumi IEEE Electr. Insul. M. 17 (2001) 6.

[45] C. Wang, A. J. Appleby, F. E. Little, J. Electroanalytical Chem. 497 (2001) 33.

[46] W. A. Schalkwijk, B. Scrosati, Adv. Lithium-Ion Batteries, Kluwer Academic/Plenum Publ., New York (2002).

[47] J. -H. Ahn, G. X. Wang, J. Yao, H. K. Liu, S. X. Dou, J. Power Sources 119 (2003) 45.

(Rec. 19/10/2007, Ac. 19/12/2007) 